\title{
Species abundance patterns of benthic macroinvertebrate communities in polluted streams
}

\author{
X.-D. Qu ${ }^{1}$, M.-Y. Song ${ }^{2}$, Y.-S. Park ${ }^{3}$, Y.N. Oh ${ }^{1,4}$, T.-S. Chon ${ }^{1 *}$ \\ ${ }^{1}$ Division of Biological Sciences, Pusan National University, Geumjeong-gu, Busan (Pusan) 609-735, Republic of Korea \\ ${ }^{2}$ West Sea Fisheries Research Institute, Jung-gu, Incheon 400-420, Republic of Korea \\ ${ }^{3}$ Department of Biology and Institute of Global Environment, Kyung Hee University, Dongdaemun-gu, Seoul 130-701, Republic of Korea \\ ${ }^{4}$ Current address: Dongnae Girls' High School, Geumjeong-gu, Busan 609-718, Republic of Korea
}

\begin{abstract}
Benthic macroinvertebrates collected at seven different streams displaying different pollution levels were used to investigate species abundance patterns in polluted streams. Community response to disturbances in streams was analysed using species abundance distribution (SAD) for benthic macroinvertebrates across different levels of pollution. The slopes of rank abundance were characteristically steeper with decreasing species richness at the polluted sample sites, while the slopes were less steep with higher species richness at the clean or slightly disturbed sample sites. The SADs were broadly fitted to the log normal distribution in benthic macroinvertebrate communities across different levels of pollution. A geometric series was partly accepted for the communities at the severely polluted sites where new species could not be readily introduced. A power law was applied to the SADs, and the parameters reflected the states pertaining to the sample sites. The SADs were also efficient in revealing ecological state of communities where physico-chemical indicators could not be easily differentiated for stressful conditions in streams.
\end{abstract}

Keywords: Species abundance distribution, benthic macroinvertebrates, log normal distribution, geometric series, power law

\section{Introduction}

Studies on species abundance patterns in communities have been initiated in conjunction with determination of species richness (the number of species) in a closed area (i.e., island biogeography) in the topics of species area relationships (SAR) (Arrhenius 1921, Gleason 1922, MacArthur \& Wilson 1967, Hubbell 2001, Puyeo 2006a). Along with SAR the structural coherence residing in relationships between species and their corresponding abundance within communities have been investigated under the topics of relative species abundance or species abundance distribution (SAD) (Motomura 1932, Fisher et al. 1943, Preston 1948, Whittaker 1975, Hubbell 1997, Harte et al. 1999, Pueyo 2006b). Extensive reviews on SAD can be found in May (1975), Hubbell (2001), Magurran (2004) and May et al. (2007). Conventionally well known models in SAD (Magurran 2004) are geometric series (Motomura 1932), log series (Fisher et al. 1943), log normal distribution (Preston

\footnotetext{
* Corresponding author: E-mail: tschon@pusan.ac.kr
}

1948, Sugihara 1980), and broken stick model (MacArthur 1957, 1960).

Theoretical interpretation of species abundance patterns was additionally carried out regarding the neutral model to elucidate identical properties of individuals to cover ecological drift and mutation (or fission) rates in $\mathrm{SAD}$ on two scales of local communities and regional metacommunities in zero-sum multinomial distribution (Hubbell 1997, Hubbell 2001, Volkov et al. 2003, McKane et al. 2004). However, debates are ongoing regarding assumptions (i.e., niche-assembly vs. dispersal-assembly) and evaluation of the model fitting to field data (McGill 2003a, Chave 2004, Pueyo 2006a, 2006b). In a separate approach, the power law in SAR (Arrhenius 1921) was revisited to elucidate the generality of self-similarity in identifying SADs (Harte et al. 1999, Pueyo 2006a, 2006b). Chave (2002) proposed a spatially explicit, individual based model to assess the effects of ecological processes to reveal degree of evenness in relative-abundance distribution. Tokita (2004, 2006) recently characterized different patterns of SADs according to energy states in statistical physics by regarding 
the replicator equation as equivalent to the model of competitive community for resources.

Experimental observations on SADs have been reported regarding community responses to changes in environmental factors. SAD in plant communities changed from the log normal distribution to the geometric series after fertilizer was added to grassland (Begon et al. 2006). In aquatic algal communities Patrick (1975) observed that the log normal distribution in SAD was converted to the log series when the amount of discharge in streams decreased. On marine benthic communities, variation in the log normal distribution including departure toward a geometric series was reported on detecting pollution induced changes (Gray \& Mirza 1979, Gray 1981). Jackson et al. (2001) further found that the log normal distribution in the microbial communities became a geometric series with increases in environmental stress. The reverse situation for recovery was also reported in the microbial communities: decrease in steepness was accompanied by a higher abundance of medium ranked species in high species richness in both lakes and mesocosms in succession processes (Jackson et al. 2001). In addition a similar trend in SAD was reported in plant community recovery on Mount St. Helens after its eruption (del Moral 1999). Although Patrick (1975) reported SAD in algal communities, not much research has been carried out on communities collected in freshwater aquatic ecosystems, while studies on SAD have been extensively conducted on terrestrial (Whittaker 1965, 1975, MacArthur 1972) and marine (Hughes 1984, Gray \& Mirza 1979, Gray 1981, Magurran \& Henderson 2003) communities.

Benthic macroinvertebrates are regarded as one of the most representative taxa for identifying ecological states in aquatic ecosystems (James \& Evison 1979, Resh \& Rosenberg 1984, Resh et al. 1995, Barbour et al. 1996). They reflect environmental changes in an integrative and continuous manner and have been widely used for ecological water quality assessment (Rosenberg \& Resh 1993, Wright et al. 2000, Chon et al. 2002, Park et al. 2007, Allan \& Castillo 2007). In this study we investigate species abundance patterns in benthic macroinvertebrates in polluted streams and elucidate how the SADs would characterize community structure and respond to environmental disturbances.

\section{Materials and methods}

\section{Study area}

The sample sites were selected from three polluted streams and four less polluted streams in Busan and
Seoul metropolitans in the Republic of Korea (Fig.1). Among three main streams, two streams were surveyed in the Suyong River basin within the Busan metropoli$\tan$ area. The Soktae Stream passed through areas exposed to a wide range of pollution including domestic sewage, agricultural practices, and small-scale industry (Fig. 1). The sample sites (T1 (Sadeung-gol; TSD), T2 (Ko-chon; TKC), T3 (Hapansong; THP), and T4 (Chung-li; TCL)) showed a pollution gradient longitudinally from upper to down stream (BOD $4.9-46.2 \mathrm{mg} /$ L, conductivity $192.7-618.5 \mu \mathrm{S} / \mathrm{cm}$ ) (Table 1). The sample sites (Y1 (Imgok: YIG), Y2 (Changki; YCK) and Y3 (Shinchon; YSC)) in the Suyong Stream were located in the intermediately polluted agricultural areas (BOD $2.8-3.7 \mathrm{mg} / \mathrm{L}$, conductivity $134.3-324.1 \mu \mathrm{S} /$ cm) (Kwon \& Chon 1991, Park et al. 2004). The Biological Monitoring Working Party (BMWP) scores were accordingly low around 3 (median) at the polluted sites, while the values were correspondingly higher in the range of 17-46 (median) at less polluted sites in the Suyong River basin (Table 1) (Kwon \& Chon 1993, Youn \& Chon 1996, Chon et al. 2000).

Since it was difficult to obtain unpolluted sites in the Suyong River basin during the survey period, we selected an additional sample site $B$ in the Paenae Stream, a tributary of the Nakdong River, in the mountain area near Busan as a reference site (Fig. 1). The sample site B is monitored for the National Long-Term Ecological Research Project in Korea in presenting a clean site in the Nakdong River basin. We also selected a polluted site K (HJD) in the Hakjang Stream, a tributary of the Nakdong River within the Busan area. The site $\mathrm{K}$ was heavily affected by domestic and industrial pollution. Environmental factors for the sites B and $\mathrm{K}$ are summarized in Table 1. The BMWP scores were correspondingly different: high at $\mathrm{B}$ with 153 and low at $\mathrm{K}$ with 27 in the median values.

Additionally benthic macroinvertebrate community data collected at the sample sites in the Yangjae Stream (Fig. 1), an extremely polluted stream in Seoul (Table 1), were also analyzed for SADs. The Yangjae Stream is one of the main tributaries of the Han River system, flowing through the commercial, domestic and agricultural areas in the southern part of Seoul (Kwak et al. 2002, Song et al. 2006). A water recovery project was conducted at the study site in the Yangjae Stream during the survey period (KICT 1997). Vegetation channel revetment was carried out in the riparian zone close to site $\mathrm{J} 2$. The stream bed was constructed using large-sized cobbles approximately $5 \mathrm{~cm}$ in diameter. Additional restoration techniques were applied to other sample locations (Kwak et al. 2002, Song et al. 2006). 


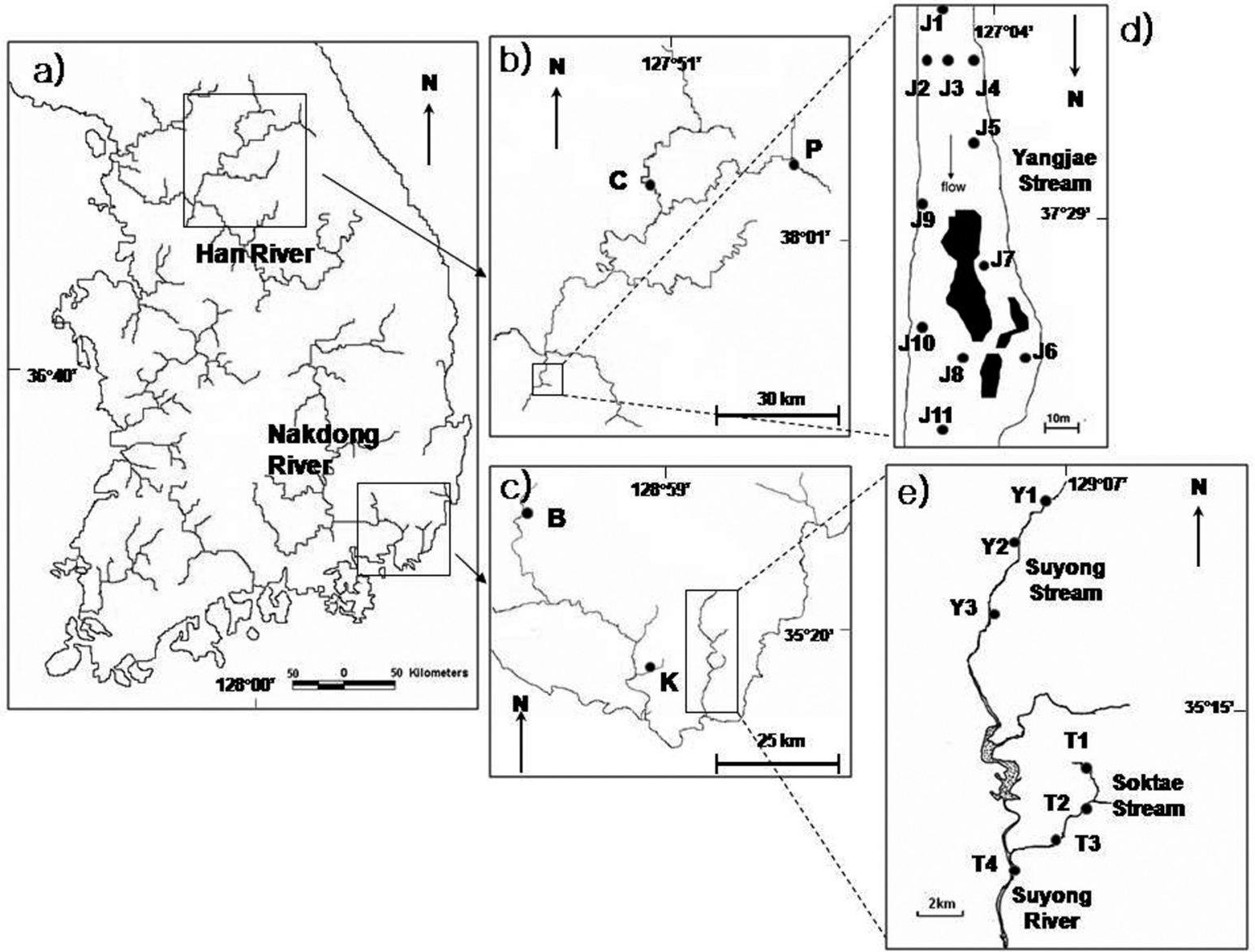

Fig. 1. Location of the sample sites in different streams in Korea. a) Korean Peninsula showing Nakdong and Han Rivers, b) Pangtae (P) and Chojong (C) Streams, c) Paenae (B) and Hakjang (K) Streams, d) Yangjae (J1-J11) Stream, and e) Soktae (T1-T4) and Suyong (Y1-Y3) Streams in Suyong River.

Since no clean site was available in the Yangjae Steam, data from two upstream sample sites (sites $\mathrm{P}$ and C) in the upper Han River basin (Fig. 1) were additionally obtained from the published articles. Site P (HPT) in the Pangtae Stream (Park \& Cho 1995) (BOD: $1.07 \mathrm{mg} / \mathrm{L})$ and site $\mathrm{C}(\mathrm{HCJ})$ in the Chojong Stream (Bae \& Park 1992) (BOD: $1.40 \mathrm{mg} / \mathrm{L}$ ) were slightly disturbed by human activities (Table 1). Although water quality values in the Pangtae Stream were reported after two years following the biological survey at site $\mathrm{P}$, it was presumable that the water quality did not change greatly in this area, since the sample sites were located in under-developed areas and were not exposed to notable disturbances during the survey period. The BMWP scores were 158 and 126 in the median values at sites $\mathrm{P}$ and $\mathrm{C}$, showing the relatively clean state (Table 1).

\section{Data collection}

Benthic macroinvertebrates were collected using a Surber sampler $\left(30 \times 30 \mathrm{~cm}^{2}, 500 \mu \mathrm{m}\right.$ mesh, excluding the Pangtae Stream; $50 \times 50 \mathrm{~cm}^{2}, 200 \mu \mathrm{mmesh}$ ) for all the sample sites in three replications (excluding five replications in the Pangtae Stream) and were identified to species or genus level. Samples were collected monthly for communities in the Suyong River basin from March, 1992 to April 1995. In the Suyong Stream, 74 samples (from 3 sampling sites for 30 months, excluding some missing samples) were obtained with collection of 10 species, while 147 samples (from 4 sampling sites for 48 months, excluding some missing samples) were collected and 112 species were identified in the Soktae Stream (Chon \& Kwon 1991, Kwon \& Chon 1991). Twenty samples (from 5 sampling sites for 4 seasons) were obtained 
Table 1. Environmental factors (mean \pm SD) and biological index (BMWP; median (range)), measured in different streams in Korea.

\begin{tabular}{|c|c|c|c|c|c|}
\hline Streams & Sites & $\mathrm{BOD}(\mathrm{mg} / \mathrm{L})$ & Turbidity (NTU) & Conductivity $(\mu \mathrm{s} / \mathrm{cm})$ & BMWP \\
\hline \multirow{4}{*}{ Soktae } & $\mathrm{T} 1$ & $4.87 \pm 4.21$ & $11.15 \pm 8.50$ & $192.70 \pm 73.31$ & $46(3-105)$ \\
\hline & $\mathrm{T} 2$ & $6.94 \pm 5.61$ & $6.12 \pm 13.24$ & $335.40 \pm 97.61$ & $17(5-36)$ \\
\hline & $\mathrm{T} 3$ & $43.23 \pm 17.35$ & $25.51 \pm 15.25$ & $571.20 \pm 151.91$ & $3(0-6)$ \\
\hline & $\mathrm{T} 4$ & $46.21 \pm 20.87$ & $22.32 \pm 15.15$ & $618.5 \pm 122.26$ & $3(0-3)$ \\
\hline \multirow{3}{*}{ Suyong } & Y1 & $3.28 \pm 3.71$ & $2.63 \pm 2.78$ & $134.30 \pm 96.24$ & $25(2-74)$ \\
\hline & $\mathrm{Y} 2$ & $2.76 \pm 2.35$ & $1.86 \pm 2.16$ & $180.40 \pm 36.86$ & $36(2-82)$ \\
\hline & Y3 & $3.72 \pm 4.46$ & $7.51 \pm 11.70$ & $325.10 \pm 156.47$ & $23(2-40)$ \\
\hline Hakjang & $\mathrm{K}$ & $32.82 \pm 31.88$ & $14.81 \pm 12.30$ & $451.90 \pm 248.42$ & $27(13-36)$ \\
\hline \multirow[t]{2}{*}{ Paenae ${ }^{1}$} & B & $0.90 \pm 0.50$ & $1.20 \pm 0.60$ & $34.46 \pm 13.37$ & $153(122-174)$ \\
\hline & $\mathrm{J}_{\mathrm{f}} 5$ & $4.67 \pm 1.50$ & $9.06 \pm 4.54$ & $413.58 \pm 68.58$ & $6(1-17)$ \\
\hline \multirow[t]{2}{*}{ Yangjae } & $\mathrm{J}_{\mathrm{s}}{ }^{5}$ & $8.58 \pm 3.69$ & $4.30 \pm 1.57$ & $402.00 \pm 60.25$ & $6(1-22)$ \\
\hline & $\mathrm{J}_{\mathrm{t}}^{5}$ & $10.67 \pm 5.84^{2}$ & $6.80 \pm 3.53^{2}$ & $350.00 \pm 78.32$ & $6(1-26)$ \\
\hline Pangtae & $\mathrm{P}$ & $1.07 \pm 0.46^{3}$ & --- & $25.00-35.00^{4}$ & $158(142-177)$ \\
\hline Chojong & $\mathrm{C}$ & $1.40 \pm 0.39^{3}$ & --- & --- & $126(104-211)$ \\
\hline \multicolumn{6}{|c|}{$\begin{array}{l}{ }^{1} \text { Conductivity measured in 2005, other factors from } 1989 \text { to } 1990 . \\
2 \text { Data from KICT (1999). } \\
{ }^{3} \text { Data from the Water Quality Monitoring Program (http:///water.nier.go.kr/) by National Institute of Environmental } \\
\text { Research (NIER), Ministry of Environment of Korea, in } 1995 \text { for P and in } 1993 \text { for C. } \\
{ }^{4} \text { Data from Park \& Cho (1995). } \\
{ }^{5} \mathrm{~J}_{\mathrm{f}}, \mathrm{J}_{\mathrm{S}} \text {, and } \mathrm{J}_{\mathrm{t}} \text { represent the first, second and third year of site J, respectively. }\end{array}$} \\
\hline
\end{tabular}

from site B in the Paenae Stream from August 1989 to May 1990 (Oh \& Chon 1991a, 1991b, 1993) with collection of 124 species, while seasonal data from the severely polluted site K in the Hakjang Stream were collected from 4 samples (from 1 sampling site for 4 seasons) with identification of 27 species from August 2006 to April 2007.

Fine scale sampling was conducted in the Yangjae Stream for a $200 \mathrm{~m}$ reach. Eleven sample sites (J1 - J11; JHU, JHA-JHJ) separated by $10 \mathrm{~m}$ increments were selected in the sampling area (Fig. 1). Monthly sampling was carried out from April 1996 to March 1999 for three years. In the Yangjae Stream, overall 32 species were recorded from 396 samples (from 11 sampling sites for 36 months). In the Pangtae Stream for reference site, forty two samples (from 7 sampling sites for 6 months) were collected from April 1992 to September 1993 with identification of 146 species, while 77 samples (from 7 sampling sites for 11 months) were obtained in the Chojong Stream from September 1992 to August 1993 with collection of 151 species.

\section{Community analysis}

Three conventional models, a geometric (Motomura 1932), a log series (Fisher et al. 1943) and a log normal distribution (Preston 1948, Magurran 2004), were selected to fit species abundance and rank relationships in the benthic macroinvertebrate communities. We did not include the broken stick model because the model is characterized with a large number of species in intermediate dominance while the curve possesses an extremely flatted medium range along with slight up-bend at the left 
part and down-bend at the right part (Magurran 2004). This pattern basically was not matched to the observed samples in this study: benthic macroinvertebrates from polluted streams are well known that a few tolerant taxa are selectively present in high abundance (Hellawell 1986, Rosenberg \& Resh 1993, Wright et al. 2000, Chon et al. 2002, Park et al. 2007, Allan \& Castillo 2007).

In the geometric series species abundance, ranked from most to least abundant, is expressed as (Motomura 1932, May 1975, Magurran 1988):

$n_{i}=N C_{k}(1-k)^{i-1}$

where $n_{i}$ is the number of individuals in the $i$ th species, $k$ is the proportion of the available resource that each species utilizes, $N$ is the total number of individuals, and $C_{k}$ is a constant insuring $\sum n_{i}=N$ (See Magurran 2004). The log series originally proposed by Fisher et al. (1943) is presented as:

$x x, \frac{a x^{2}}{2}, \frac{a x^{3}}{3}, \ldots, \frac{a x^{n}}{n}$

where $\alpha$ is the index of diversity, $n$ is species sequence from the minimum to the maximum, and $x$ is estimated from the iterative solution of

$S / N=(1-x) / x[-\ln (1-x)](S$; the total number of species, and $N$; the total number of individuals).

The log normal distribution (Preston 1948, May 1975) illustrates that frequency of species arranged on the logarithm scale of species abundance follows the normal distribution as:

$S(R)=S_{0} \exp \left(-a^{2} R^{2}\right)$

where $S(R)$ is the number of species in the $R$ th octave (i.e. class) in abundance to the right and left of the symmetrical curve and $S_{0}$ is the number of species in the modal octave. The parameter $a$ indicates the inverse width of the distribution: $a=\left(2 \sigma^{2}\right)^{1 / 2}$ where $\sigma$ is the standard deviation of the observed values after taking logarithm (Preston 1948, May 1975). In this study, the truncated log normal distribution was used to fit to the community data based on Magurran (2004).

Parameters (e.g., $k$ in the geometric series, $x$ in the log series) in the models were estimated based on iterative calculation (see May (1975) and Magurran (2004)) for detailed procedure). After estimation of the parameters, the Kolmogorov-Smirnov test for goodness of fit (Sokal $\&$ Rohlf 1995) was conducted according to methods proposed by Magurran (2004; see Worked examples) for the models of geometric, $\log$ series and log normal distribution. Tokeshi (1993) advocated adopting the Kolmogorov-Smirnov goodness of fit test as the standard method of assessing the goodness of fit of deterministic models, and the method has been efficiently used for evaluating the fitness of the models in species abundance patterning (Magurran 2004).

In order to check the structural property of the sampled communities, the power law was applied (Pueyo 2006a, 2006b):

$p(n) \propto n^{-\beta}$

where $p(n)$ is the probability density of $n$ individuals in communities, and $\beta$ is a constant. According to Pueyo (2006b), $p(n)$ is replaced with $f(n)$ as a continuum of probability densities, and the value in each bin $j$ was estimated in our study as:

$f\left(n_{j}\right)=\frac{1}{2^{j}} \frac{s_{j}}{S}$

where $s_{j}$ is the number of species in bin $j$ for the abundance class (in this case, interval $=2$ ), $2^{j}$ indicates the width of bin $j$, and $S$ is the total number of species. For each bin $j$ the (logarithmically) central value is $n_{j}=2^{j+\frac{1}{2}}$. The Taylor expansion was applied to estimate departure from the observed data and the power law, and the maximum likelihood estimation was used to estimate the $\beta$ values (Pueyo 2006b):

$$
f(n)=\left[\frac{\beta-1}{n_{0}^{-\beta+1}-n_{M}^{-\beta+1}}\right] * n^{-\beta}
$$

where $n_{0}$ and $n_{M}$ are the lower and upper bounds of the number of individuals. In our study, $n_{0}$ was the number of minimum individuals while $n_{M}$ was selected as the number of second dominant species to cope with the departure problem from the power law at the abundance in the maximum range (i.e., bending effect) constrained by community size (See Pueyo 2006b). The linear regression analysis was additionally applied to estimation of the parameter over the whole range of abundance. Detailed methods for estimating the $\beta$ values could be referred to Pueyo (2006b). 


\section{Results}

\section{SAD curves}

Patterns of species abundance distribution in the Suyong River basin reflected the state of pollution at the sample sites (Fig. 2a). The SAD curves presented in the relationships between species rank and abundance in logarithm were in accordance with values of environmental factor. The SADs identifying extremely polluted sites, T3 and T4, in the Soktae Stream (Table 1) were distinctively separated from other SADs. The curves were steeper, and the number of species was in the lower range with 19-22 species (Fig. 2a). At the intermediately polluted site, T2, in the Soktae Stream, the curve was different from that of polluted sites, T3 and T4 (Fig. 2a). The slope was less steep and showed a relatively higher range of the number of species with 66 species.

The curve for the relatively clean site, $\mathrm{T} 1$, in the Soktae Stream was distinctively less steep and showed the highest level of species richness with 91 species (Fig. 2a). Although there were no conventional pollution sources in this area, a public cemetery was located near the sample site T1. Deforestation conducted at the cemetery provided places for tombs. Consequently, the site was intermittently exposed to disturbance resulting from silt deposition. Turbidity at $\mathrm{T} 1$ was accordingly higher with 11.15 NTU on average reflecting disturbances from development of the public cemetery (Table 1).

The three sample sites (Y1-Y3) for the Suyong Stream showed a similar pattern in SAD (Fig. 2b), and was in accordance with intermediately polluted sites T2 (Fig. $2 a)$. The slopes were less steep and showed a relatively higher range in the number of species (66 at T2, and 91 at Y2). The sample sites in the Suyong Stream appeared to be slightly less polluted compared with site T2 (Table 1).

Although the environmental values were similar among the three sample sites, the differences were still observed at a fine scale within the sample sites in the Suyong Stream. Site Y3, the most polluted state among the three sites (Table 1), was accordingly placed in the lowest position in the curves for species rank and abundance (Fig. 2b), matching values of environmental factors (Table 1). The two sites, Y1 and Y2, however, were not clearly differentiated with respect to environmental factors. While conductivity indicated higher disturbance at $\mathrm{Y} 2$, the other indicators such as BOD, turbidity and BMWP tended to present better quality at the same site (Table 1). Although the sample sites were not clearly differentiable based on the environmental data (Table 1), the SAD curves appeared consistently higher at site $\mathrm{Y} 2 \mathrm{com}-$ pared with Y1 (Fig. 2b). Overall field experiences (e.g.,

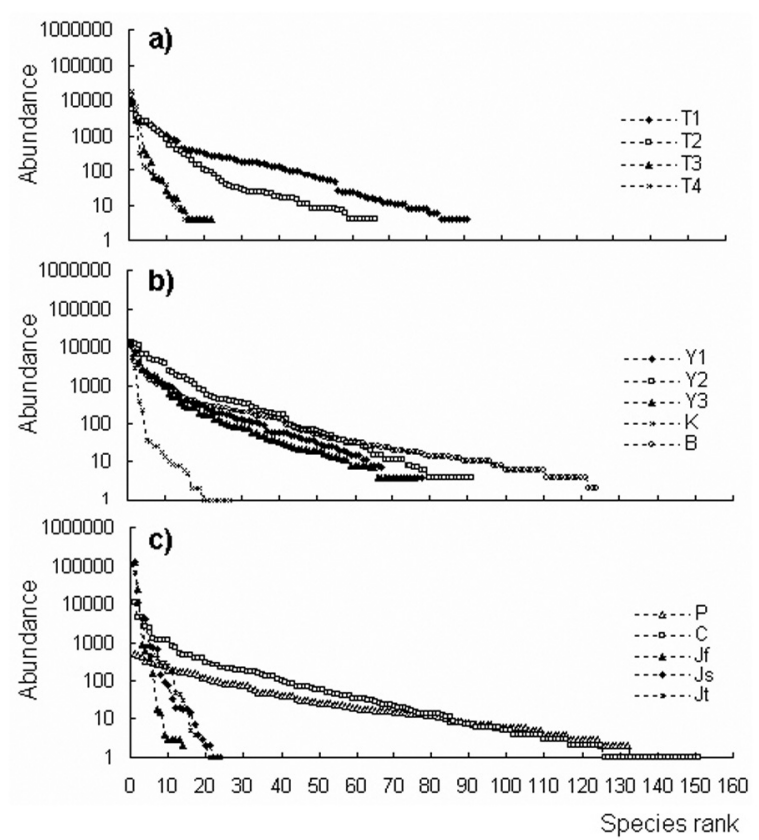

Fig. 2. Species abundance distribution in relation to species rank in benthic macroinvertebrate communities across different levels of pollution. a) Soktae Stream, b) Suyong, Hakjang and Paenae Streams, and c) Yangjae, Pangtae and Chojong Streams.

appearance of water body, surrounding environment) also matched to the state (less-disturbed) of the sample sites in the order of Y2, Y1, and Y3 during the survey period.

SAD for site B of the Paenae Stream appeared flatter and the number of species was higher with around 125 species (Fig. 2b). On the other hand, the extremely polluted site K (Table 1, Fig. 2b) in the Hakjang Stream showed a similar pattern to polluted sites T3 and T4 in the Soktae Stream (Table 1, Fig. 2a) with a steep slope and low number of species at around 20 species, although the sample size was relatively smaller at this site.

The Kolmogorov-Smirnov goodness of fit test was conducted to evaluate the fitness of the species abundance distribution at different sample sites with three different models: geometric series, $\log$ series, and $\log$ normal distribution (Table 2). All sample sites covering polluted and clean states in the Suyong River basin showed the log normal distribution $(p>0.25)$, while they were not fitted with the other models, geometric series and $\log$ series, with high significance $(p<0.001$ except for log series in the Chojong Stream $(p<0.05))$.

SADs in the Yangjae Stream showed steep slopes and reduced number of species (14 - 22) during the survey period (Fig. 2c), similar to curves from polluted sites 
Table 2. Statistical values of Kolmogorov-Smirnov test for goodness of fit for three different models in species abundance distribution of benthic macroinvertebrate communities in the Suyong River and the reference sites.

\begin{tabular}{lcccc}
\hline Streams & Sites & $\begin{array}{c}\text { Geometric } \\
\text { series }\end{array}$ & Log series & $\begin{array}{c}\text { Log normal } \\
\text { distribution }\end{array}$ \\
\hline Soktae & $\mathrm{T} 1$ & $0.2165 * *$ & $0.1810 * *$ & 0.0548 \\
& $\mathrm{~T} 2$ & $0.2450 * *$ & $0.1496 * *$ & 0.0784 \\
& $\mathrm{~T} 3$ & $0.3371 * *$ & $0.1942 * *$ & 0.1303 \\
& $\mathrm{~T} 4$ & $0.3895 * *$ & $0.2658 * *$ & 0.1278 \\
\hline Suyong & $\mathrm{Y} 1$ & $0.3436 * *$ & $0.1499 * *$ & 0.0379 \\
& $\mathrm{Y} 2$ & $0.1811 * *$ & $0.1091 * *$ & 0.0426 \\
& $\mathrm{Y} 3$ & $0.3342 * *$ & $0.1137 * *$ & 0.0602 \\
\hline Hakjang & $\mathrm{K}$ & $0.4635 * *$ & $0.2684 * *$ & 0.0609 \\
Paenae & $\mathrm{B}$ & $0.3142 * *$ & $0.1608 * *$ & 0.0510 \\
Pangtae & $\mathrm{P}$ & $0.1324 * *$ & $0.1185 * *$ & 0.0315 \\
Chojong & $\mathrm{C}$ & $0.3794 * *$ & $0.0758 *$ & 0.0358 \\
\hline$* p<0.05$ & & & & \\
\hline$* * p<0.001$ & & & & \\
\hline
\end{tabular}

observed in the Suyong River (Fig. 2a). The relatively clean sites $\mathrm{P}$ and $\mathrm{C}$ in the upstream area in the Han River, however, characteristically showed patterns found at the clean site with less-steep slopes and higher number of species at over 146 species (Fig. 2c). Compared with site $\mathrm{P}$, the SAD for slightly enriched site $\mathrm{C}$ had a steeper slope and higher number of species. Environmental factors were accordingly different between sample sites in the Yangjae Stream and the reference sites P and C (Table 1).

Variation in SADs in the different sampling locations and times in the Yangjae Stream was further evaluated. Sample sites were divided according to the upstream (J1-J5) and downstream (J6-J11) areas (Fig. 3). The slopes for the curves for all SADs in both the upstream and downstream areas in the first year were steeper with low species richness compared with the second and third years. Although environmental factors have not distinctively changed (Table 1), the number of species characteristically increased from the first (8-10) to the following (10-16) years (Fig. 3). The SADs clearly illustrated the changes in community structure in the sampling period: slope steepness substantially decreased while the tails showing low-rank species (in the right band side of the SAD curve) were more introduced in the second and third years. All sample sites accordingly showed these similar differences in pattern, suggesting that ecological states could be feasibly presented with SADs in a stable manner, although physico-chemical indicators were not clearly differentiable in presenting water quality (Table 1). Community changes reflected the impact of the restoration project conducted in the Yangjae Stream. Biological index, BMWP score, increased in the second and third years (Table 1), although the increase was not substantial.

The differences in the number of species were revealed at different sample sites (Fig. 4). The number of species at the upstream sample sites (mainly sites J1 and J2) was higher than the number of species at the downstream sites. Especially the sample site J2, where the revetment project for restoration was performed, showed the highest number of species with 6.5 on average (Song et al. 2006). The total number of species of sites $\mathrm{J} 1$ and $\mathrm{J} 2$ was significantly higher compared with those of other sites, while species richness at the downstream sites J6, J8 and J11 was significantly lower $(p<0.05$; Tukey test) (Fig. 4).

SADs in the Yangjae Stream were fitted to different models in different years. The geometric series were accepted to all sample sites for the first year, while the log series and log normal distribution were rejected for this year (Table 3). For the second and third years, in contrast, the log normal distribution was fitted to most sample sites, while the log series was partly accepted and geometric series was rejected for most sample sites in this period. Sample sites $P$ and $C$ in the upstream Han River were fitted to the log normal distribution, while the geometric and log series were rejected (Table 2).

The log normal distribution matched most community data in both Suyong River basin and Yangjae Stream. The two indices, $a$ and $\gamma$ (May \& McLean 2007), were calculated to characterize the log normal distribution according to Magurran (2004) (Table 4). The $a$ and $\gamma$ values at all study sites except the Yangjae Stream were close to 0.2 and 1.0 respectively as expected from the canonical log normal distribution (May et al. 2007). At samples sites in the Yangjae Stream, however, the values were different. In the first year, $a$ was substantially lower at 0.14 , whereas $\gamma$ was higher at 1.95 . In the following years when SADs were mostly fitted to the log normal distribution (Table 3) $a$ values $(0.16-0.17)$ increased, whereas $\gamma$ values (1.49-1.60) decreased (Table 4). At the clean and less polluted reference sites ( $\mathrm{B}, \mathrm{C}$, and $\mathrm{P}$ ), the parameters were in the range expected from the canonical log normal distribution. The parameter $a$ tended to be slightly higher 

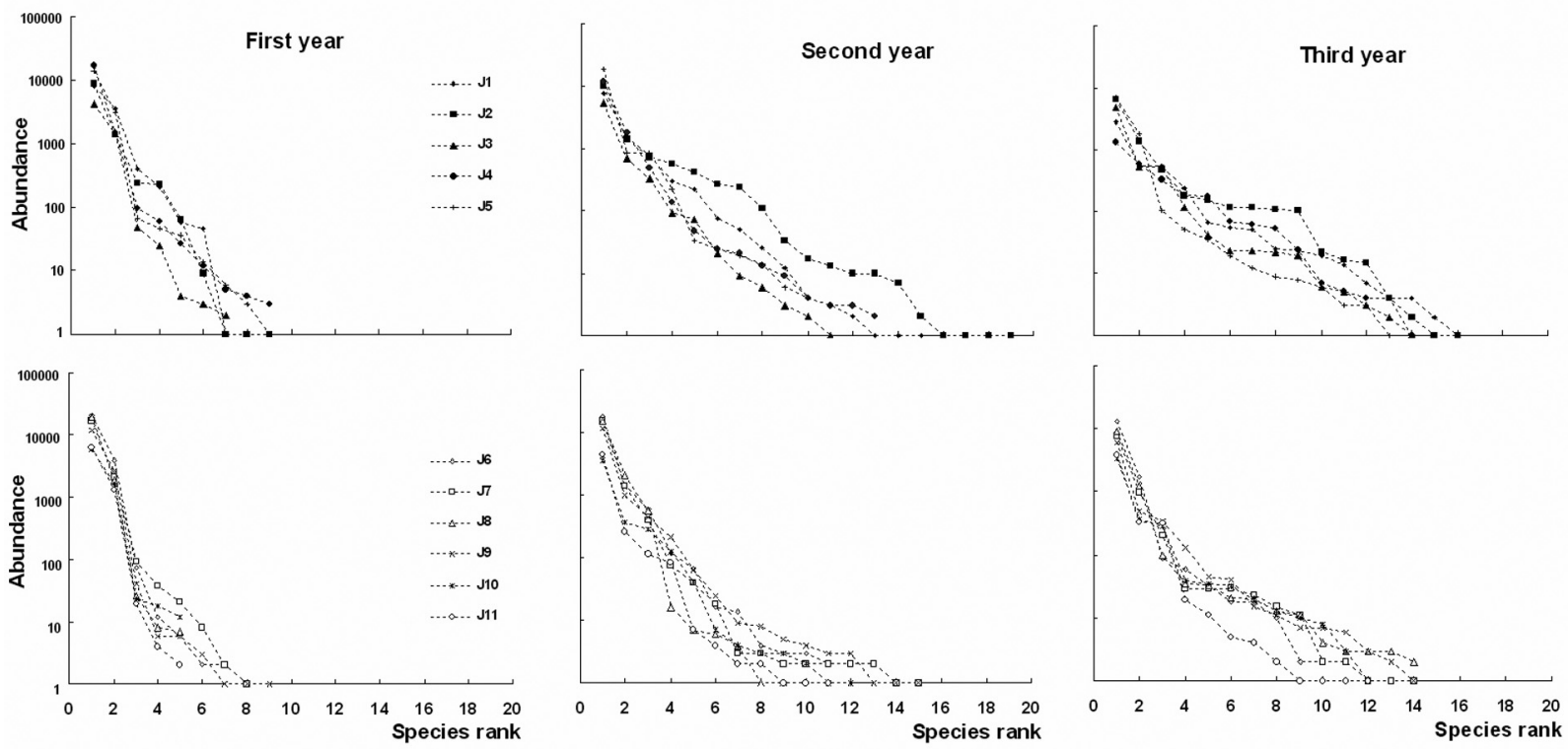

Fig. 3. Species abundance distribution in relation to species rank in benthic macroinvertebrate communities collected in different sampling locations and times in Yangjae Stream.

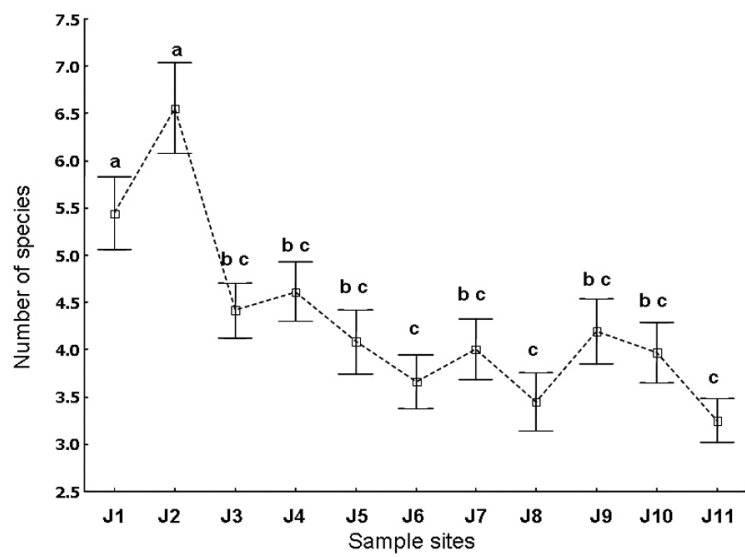

Fig. 4. Variation in species richness in benthic macroinvertebrate communities collected at different sample sites in Yangjae Stream.

(0.25-0.35) and $\gamma$ appeared to be lower (0.56-0.77). At the polluted reference site $\mathrm{K}$, the parameters were also in the similar range $(a=0.24, \gamma=0.93)$ to the canonical distribution. The other parameters for the models measured in the Suyong River (and reference sites) and in the Yangjae Stream are listed in Appendix I and Appendix II respectively.

\section{Application of power law}

The power law (Pueyo 2006a, 2006b) was additionally applied to check community structure in benthic macroinvertebrates in polluted streams. The $\beta$ values based on the maximum likelihood estimation were characteristically lower in the polluted Yangjae Stream (1.10-1.12) compared with the streams in the Suyong River (1.21-1.35) including the polluted sites (Table 5). The $\beta$ values for the clean and less-polluted references sites were higher at $\mathrm{B}(1.38), \mathrm{P}(1.34)$ and $\mathrm{C}(1.25)$. At the extremely polluted Hakjang Stream, however, the $\beta$ value was also higher at 1.27. Considering that the value was low at the polluted Yangjae Stream while the value was high at site $\mathrm{K}$, the parameters presented separately the community state pertaining to different streams (Table 5).

The power law with regression analyses showed a similar trend to that with the maximum likelihood estimation (Table 5). Although the $\beta$ values obtained from the regression analyses were lower compared with those from the maximum likelihood estimation, the difference between the Yangjae and other streams was still maintained. The $\beta$ values of the Suyong and Soktae streams were lower(1.13-1.32) but the values appeared to be even lower in the Yangjae Stream (1.05-1.10).

It was notable that $\beta$ values tended to decrease at the polluted sites in the same stream on a fine scale, although 
Table 3. Statistical values of Kolmogorov-Smirnov test for goodness of fit for three different models in species abundance distribution of benthic macroinvertebrate communities at different samples sites in the Yangjae Stream in three years.

\begin{tabular}{|c|c|c|c|c|c|c|c|c|c|}
\hline \multirow[b]{2}{*}{ Sites } & \multicolumn{3}{|c|}{ Geometric series } & \multicolumn{3}{|c|}{ Log series } & \multicolumn{3}{|c|}{ Log normal distribution } \\
\hline & $1^{\text {st }} \mathrm{yr}$ & $2^{\text {nd }} \mathrm{yr}$ & $3^{\text {rd }} \mathrm{yr}$ & $1^{\text {st }} \mathrm{yr}$ & $2^{\text {nd }} \mathrm{yr}$ & $3^{\text {rd }} \mathrm{yr}$ & $1^{\text {st }} \mathrm{yr}$ & $2^{\text {nd }} \mathrm{yr}$ & $3^{\text {rd }} y r$ \\
\hline $\mathrm{J} 1$ & 0.1339 & $0.2624 * *$ & $0.2453 *$ & $0.3468 * *$ & 0.0946 & $0.2093 *$ & 0.1643 & 0.0956 & 0.0742 \\
\hline $\mathrm{J} 2$ & 0.1486 & $0.3460 * *$ & $0.2844 * *$ & 0.1757 & 0.0884 & 0.1813 & 0.2119 & 0.1519 & $0.2567 * *$ \\
\hline $\mathrm{J} 3$ & 0.0642 & $0.2516 *$ & $0.3305 * *$ & $0.2574 *$ & 0.1447 & 0.1381 & $0.2891 * *$ & 0.1114 & 0.0983 \\
\hline $\mathrm{J} 4$ & 0.2631 & $0.3274 * *$ & 0.0447 & 0.2100 & 0.1785 & $0.2853 * *$ & 0.2023 & 0.1786 & 0.1049 \\
\hline J5 & 0.1191 & $0.3617 * *$ & $0.2652 *$ & 0.1853 & $0.2012 *$ & $0.2261 *$ & 0.1741 & 0.1269 & 0.1479 \\
\hline J6 & 0.0531 & $0.3775 * *$ & $0.3095 * *$ & $0.2501 *$ & 0.1870 & $0.2443 * *$ & $0.2812 * *$ & $0.2296 *$ & 0.1520 \\
\hline $\mathrm{J} 7$ & 0.1380 & $0.4110 * *$ & $0.3789 * *$ & 0.2120 & $0.3752 * *$ & $0.2364 * *$ & 0.2016 & 0.1793 & $0.1983 *$ \\
\hline J8 & 0.0497 & 0.1615 & $0.4080 * *$ & $0.3947 * *$ & 0.2137 & $0.2460 * *$ & $0.3374 * *$ & 0.1808 & $0.1912 *$ \\
\hline J9 & 0.1277 & $0.4033 * *$ & $0.3847 * *$ & $0.3171 * *$ & $0.2241 * *$ & 0.1684 & 0.3184 & 0.1100 & 0.1103 \\
\hline $\mathrm{J} 10$ & 0.0375 & $0.3059 * *$ & $0.3042 * *$ & $0.4175 * *$ & 0.1601 & 0.1790 & $0.3774 * *$ & 0.1838 & 0.1050 \\
\hline $\mathrm{J} 11$ & 0.0416 & $0.3549 * *$ & $0.3424 * *$ & $0.3762 * *$ & $0.2233 *$ & $0.2457 * *$ & $0.4022 * *$ & 0.1677 & 0.1516 \\
\hline All & $0.2710 * *$ & $0.4655 * *$ & $0.4084 * *$ & $0.2216 *$ & $0.1587 *$ & 0.1566 & $0.2032 *$ & 0.0746 & 0.1140 \\
\hline
\end{tabular}

the values were variable in different streams (e.g., T4 vs. $\mathrm{K}$; Table 5). The $\beta$ values at the polluted sites, T3 and T4, in the Soktae Stream (1.16-1.18) were lower compared with the less polluted sites, T1 and T2, (1.27-1.29) in the same stream. The $\beta$ values in the Yangjae Stream were significantly lower in the first year than in the following years $(p<0.05$; Tukey test) although the changes were observed on a fine scale (Fig. 5), showing the recovery progress of the water quality after the restoration project.

\section{Discussion}

SADs in this study revealed two notable points in community patterns of benthic macroinvertebrates in streams. First the log normal distribution was mostly accepted for the benthic macroinvertebrate communities in streams (Tables 2, 3), and second the geometric series was limitedly observed at the extremely polluted sites. The log normal model is frequently reported in communities where a large number of variables are involved to produce the normal patterns in species abundance accor- ding to the central limit theorem (May 1975, Sugihara 1980, Magurran 2004, May et al. 2007). In our study the log normal model was observed both for the clean sites and polluted sites, even at highly polluted T3 and T4 in the Suyong River basin (Table 2). In the polluted Yangjae Stream most sampled communities were also matched to the log normal distribution in the second and third years, although the samples collected in the first year presented the geometric series (Table 3 ). The observation was similar to the case reported by Gray and Mirza (1979) in marine benthic communities: the log normal distribution was dominantly observed with partial departure toward the geometric series in pollution-induced disturbance.

The log normal distribution could be characterized by the parameters $a$ and $\gamma$ (May 1975, Magurran 2004, May et al. 2007). The parameter $a$ expresses inverse of the width of distribution, $\left(2 \sigma^{2}\right)^{1 / 2}$, while $\gamma=\frac{R_{N}}{R_{\max }}$ indicates degree of coherence of the octave for the most abundant species $\left(R_{\max }\right)$ in species curve and the modal 
Table 4. Parameters characterizing the log normal distribution in species abundance distribution of benthic macroinvertebrate communities collected in the Suyong River, Yangjae Stream, and reference sites in Korea.

\begin{tabular}{cccc}
\hline Streams & Sites & $a$ & $\gamma$ \\
\hline Soktae & T1 & 0.25 & 0.82 \\
& T2 & 0.24 & 0.91 \\
& T3 & 0.21 & 1.21 \\
& T4 & 0.21 & 1.31 \\
\hline Suyong & Y1 & 0.24 & 0.90 \\
& Y2 & 0.21 & 1.06 \\
& Y3 & 0.24 & 0.94 \\
\hline Yangjae & $\mathrm{J}_{\mathrm{f}}$ & 0.14 & 1.95 \\
& $\mathrm{~J}_{\mathrm{s}}$ & 0.17 & 1.60 \\
& $\mathrm{~J}_{\mathrm{t}}$ & 0.18 & 1.49 \\
& $\mathrm{All}$ & 0.16 & 1.58 \\
\hline Hakjang & $\mathrm{K}$ & 0.24 & 0.93 \\
\hline Paenae & $\mathrm{B}$ & 0.26 & 0.77 \\
\hline Pangtae & $\mathrm{P}$ & 0.35 & 0.56 \\
\hline Chojong & $\mathrm{C}$ & 0.25 & 0.73 \\
\hline
\end{tabular}

octave $\left(R_{N}\right)$ in individual curve (May et al. 2007). The range of $a(0.14-0.35)$ and $\gamma(0.56-1.95)$ in this study were generally in accordance with previous reports $(a$; $0.1-0.4, \gamma ; 0.6-1.8$ ) fitted to the log normal distribution (May 1975, May et al. 2007). At some sample sites, however, the parameters deviated from these values. In the polluted Yangjae Stream $a$ 's $(0.14-0.18)$ were in the minimal range while $\gamma$ 's showed the maximal range (1.49-1.95). The values of parameters reflected species abundance patterns of the communities collected in the Yangjae Stream: a few exceptionally dominant species of the tolerant taxa (i.e., Limnodrilus sp. and Chironomus sp.) were collected at the sample sites and could contribute to increase in width of distribution and position of $R_{N}$ to a relatively higher value (i.e., $\gamma>1$ ) in community data. It was understandable that the parameters in the Yangjae Stream in the first year $(a=0.14, \gamma=1.95)$ were far from the values generally expected in the log normal distribution, since the communities collected in the Yangjae Stream in the first year belonged to the geometric series (Table 3).

It was notable that $\gamma$ values at the polluted sites tended to be higher in the same stream. The values at sites T3 and
T4 tended to increase (1.21-1.31) compared with other sites in the Soktae Stream. A similar trend was also observed in the Yangjae Stream (Table 4). $\gamma$ 's in the first year (1.95) were substantially higher than the values in the second and third years (1.49-1.60) as stated above. In polluted marine benthic communities, Gray and Mirza (1979) reported that the slope between the cumulative percent of species and abundance (in geometric classes) decreased; the decrease in the slope (i.e., less increase in species) along with the rapid increase in total abundance may have a similar impact on the log normal distribution.

It is well known that the geometric series identifies communities under stressed conditions based on resource removal with low species richness (Magurran \& Henderson 2003, May et al. 2007). In this study the geometric series was observed in one polluted stream, the Yangjae Stream, in the first year (Table 3, Figs. 2, 3). The stress of organic pollution caused significant effects on community structure. In polluted conditions interstitial space of substrates in stream bed would be filled with organic sediments to eliminate benthic organisms suitable for living in the space between the substrates. A limited number of tolerant species would be allowed to survive by pre-empting resources under severely polluted conditions.

However, this type of geometric series was not accepted for the remaining polluted sites including T3 and T4 in the Soktae stream and K in the Hakjang Stream (Table 2). As shown in Figure 2, the slopes for the abundance-rank curves were steep and the number of species was in the minimal range for the geometric series shown in the Yangjae Stream. In contrast, for communities at polluted sites T3 and T4 in the Soktae Stream species with low abundances (i.e., higher rank) also occurred. This produced the short tails of the SAD curves at the right hand side (Fig. 2a). This type of tail was also observed at site K in the Hakjang Stream. Occurrence of tails at T3 and T4 may be due to influx of species from upstream (e.g., Pseudoorthocladius sp. and Parametriocnemus sp.). Since the stream is relatively short and the stressed area is limited to around the sampling area, species from upstream could readily drift into the sampling area. For sample sites in the Yangjae Stream, however, the area of stress is wide and the stream flows through a broad disturbance area. There was relatively a lower chance of drifting from cleaner upstream areas. This difficulty in receiving new species in the Yangjae Stream contributed to fitting the SADs to the geometric series in the first year.

In the second and third years in the Yangjae Stream, however, lower abundant species (i.e., higher rank) were eventually observed in monitoring during the period of 
Table 5. Statistics of power law analysis applied to species abundance distribution of benthic macroinvertebrate communities in different streams in Korea. $N_{T}$ : total number of individuals, $S$ : total number of species, $\beta$ : "slope" parameter of the power law.

\begin{tabular}{|c|c|c|c|c|c|c|c|}
\hline \multirow{2}{*}{ Streams } & \multirow{2}{*}{ Sites } & \multirow{2}{*}{$N_{T}$} & \multirow{2}{*}{$S$} & \multicolumn{2}{|c|}{$\begin{array}{c}\text { Maximum likelihood } \\
\text { estimation }\end{array}$} & \multicolumn{2}{|c|}{ Linear regression } \\
\hline & & & & $\beta$ & $\begin{array}{l}\text { 95\% Confidence } \\
\text { interval }\end{array}$ & $\beta$ & $R^{2}$ \\
\hline \multirow[t]{4}{*}{ Soktae } & $\mathrm{T} 1$ & 36225 & 91 & 1.28 & $1.12-1.45$ & 1.27 & $0.97 * *$ \\
\hline & $\mathrm{T} 2$ & 27904 & 66 & 1.34 & $1.19-1.49$ & 1.29 & $0.98 * *$ \\
\hline & $\mathrm{T} 3$ & 17836 & 22 & 1.21 & $0.98-1.45$ & 1.18 & $0.98 * *$ \\
\hline & $\mathrm{T} 4$ & 24647 & 19 & 1.29 & $1.04-1.55$ & 1.16 & $0.97 * *$ \\
\hline \multirow[t]{3}{*}{ Suyong } & Y1 & 48609 & 78 & 1.32 & $1.23-1.42$ & 1.13 & $0.99 * *$ \\
\hline & $\mathrm{Y} 2$ & 96351 & 91 & 1.26 & $1.16-1.36$ & 1.17 & $0.99 * *$ \\
\hline & Y3 & 43578 & 76 & 1.35 & $1.28-1.43$ & 1.32 & $0.99 * *$ \\
\hline \multirow[t]{4}{*}{ Yangjae } & $\mathrm{J}_{\mathrm{f}}$ & 158581 & 14 & 1.12 & $0.95-1.30$ & 1.05 & $0.98 * *$ \\
\hline & $\mathrm{J}_{\mathrm{s}}$ & 144191 & 24 & 1.10 & $0.96-1.24$ & 1.07 & $0.98 * *$ \\
\hline & $\mathrm{J}_{\mathrm{t}}$ & 82155 & 22 & 1.12 & $1.01-1.23$ & 1.09 & $0.99 * *$ \\
\hline & All & 384927 & 32 & 1.16 & $1.06-1.27$ & 1.10 & $0.99 * *$ \\
\hline Hakjang & $\mathrm{K}$ & 9594 & 27 & 1.27 & $1.16-1.37$ & 1.22 & $0.99 * *$ \\
\hline Paenae & B & 40013 & 124 & 1.38 & $1.25-1.52$ & 1.29 & $0.95 * *$ \\
\hline Pangtae & $\mathrm{P}$ & 7436 & 146 & 1.34 & $1.18-1.51$ & 1.32 & $0.95 * *$ \\
\hline Chojong & $\mathrm{C}$ & 41533 & 151 & 1.25 & $1.08-1.43$ & 1.32 & $0.99 * *$ \\
\hline
\end{tabular}

longer survey: the SAD curves produced longer tails at right hand side with higher species richness levels (Fig. 3 ). Newly collected specimens in the second and third years presented intolerant genera such as Orthocladius, Cricotopus, and Baetis and were indicators of recovery of water quality (Hellawell 1986). Addition of species in low abundance appeared to contribute to rejection of the geometric series under stressful conditions. In the stream conditions where species could readily drift from upstream, caution may be needed in applying the geometric series in SAD. It can be hypothesized that a geometric series could be rejected at sample sites where new species could be easily introduced or drift from upstream. However, further experiments are required to confirm direct relationships between colonization of drifting species and corresponding changes in SADs. The results, however, demonstrated SADs can indeed be sensitive and are efficiently used to illustrate different community states depending upon the environmental conditions of the streams.
The SAD for all sample sites collected in the first year in the Yangjae Stream was not fitted to the geometric series, although SAD for each sample site showed the geometric series as stated above (Table 3). As data for all the sampling sites were pooled, species richness at low abundance correspondingly produced a longer tail in the curve (Fig. 2a). Consequently, the geometric series was rejected for communities covering all sample sites in the Yangjae Stream in the first year. This also supported that additional species in low abundance contributed to rejection of the geometric series in SAD under stressful conditions. This difference in model fitness would be further related to the problem of pooling data from different sampling locations, and could be extended to the issues dealing with SAR. Future study may be needed in this regard.

The log series in the SAD models was only limitedly accepted to the community data in this study. The model was partially accepted at the sample sites in the Yangjae Stream (Table 3), while the sample sites in the Suyong Stream were not fitted to the log series in all cases (Table 
2). Communities composed of a small number of abundant species and a large number of rare species could be identified by the log series (Magurran 2004). This situation did not fit community data of benthic macroinvertebrates collected at the disturbed sample sites where a few tolerant species were selectively dominant in this study. The log series would be more suitably expected if SADs are assumed on neutral theory (Hubbell 2001, Volkov et al. 2003, Pueyo 2006b). Although the log series was limitedly observed in this study as stated above, it is early to conclude not to consider the neutral model as a candidate for identifying SAD in benthic macroinvertbrate communities. The "geometric-like" or "log normal-like" distributions could be also observable from zero-sum multinomial distribution proposed in the unified theory according to different ranges in parameters. With biodiversity parameter $(\theta)$ and immigration rate $(m)$ in the minimum range, for instance, the curve for abundance and species rank could appear as "geometric-like" (Hubbell 2001). Similarly the abundance pattern could be "log-normal like" depending upon different degrees of dispersal rates and related parameters through zero-sum random drift processes (Hubbell 2001, Volkov et al. 2003). The "log normal-like" is not exactly the log normal distribution: the former is discrete with a long-attenuated tail of rare species compared with the latter. However, two models may not be readily differentiated when the data are approximated in discrete intervals and when the right hand side of the curve (i.e., species with higher abundance) is only compared (Hubbell 2001).

In this study, however, not many rare species were collected at the sample sites. It is understandable that many species in low abundance were not collected at the polluted sites. It has been reported in a numerous accounts that only the tolerant species are selectively collected in disturbed streams (Hellawell 1986, Rosenberg \& Resh 1993, Wright et al. 2000, Allan \& Castillo 2007). At clean sites, however, the full scope of rare species could not be easily disclosed, since sampling of benthic macroinvertebrate communities in stream conditions is a difficult task. In this regard attention should be more given to increase in sampling efficiency in conjunction with other related topics on complex situation of stream ecosystems such as stream flow, patch in spatial distribution, river system, impact of watershed area, and the river continuum concept. Along with increase in sampling efficiency, the parameters such as immigration rate (e.g., drifting rate) and local community size should be further considered to test the neutral model in the future.

According to the field data shown in this study, a power law accordingly presented the state of communities at different sample sites and would be feasible in revealing community structure in benthic macroinvertebrates in polluted streams in a broad scope (Table 5). The $\beta$ values in a power law presented characteristics pertaining to the sample sites. The low values, around 1.0, in the Yangjae Stream suggested that the polluted conditions would be different from other streams where the $\beta$ values were relatively higher (Table 5). It was also notable that different approaches provided congruent results for the sample sites of the geometric series (Table 3) matching to the power law with $\beta$ values close to 1 (Table 5), considering that a geometric series would be equivalent to a power law with its parameter close to 1 . Although the log series was only partly observed at the sample sites in the Yangjae Stream (Table 3), the $\beta$ values close to 1.0 may additionally indicate that SADs could be related to neutrality (Pueyo 2006b). This also supports to check feasibility of neutral theory as a special case in polluted, urban streams where dispersal-assembly would be strongly constrained (i.e., minimization of both diversity parameter and immigration rate from upstream). Regarding changes in community state, it was also notable that $\beta$ values were different at the same sites in different years in the Yangjae Stream(Fig. 5). The values were consistently lower in the first year, although the range was small. SAD indicated changes in community states although environmental factors were not improved greatly after the restoration project (Table 1). Improvement of habitat conditions was observed with higher values in species richness and biological indices in the Yangjae Stream (Song et al. 2006). The increase in $\beta$ values confirmed that SADs accordingly reflect changes in community states.

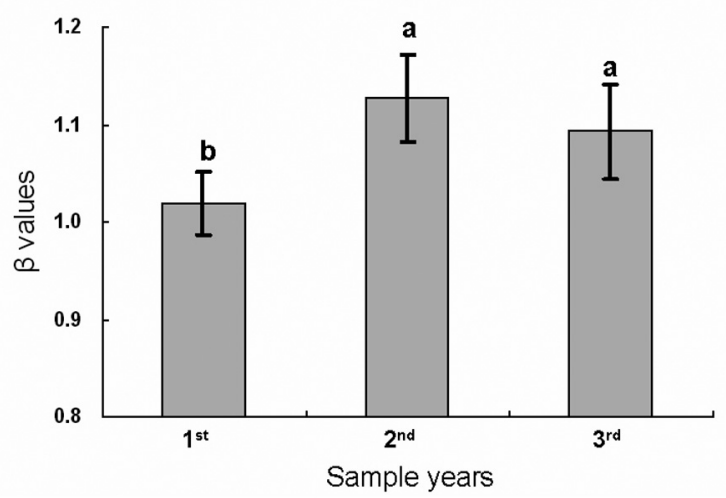

Fig. 5. The $\beta$ values in a power law with maximum likelihood estimation species abundance distribution of benthic macroinvertebrates collected in different sampling locations and times in Yangjae Stream. 
Considering close relation of SADs to log normal distribution and a power law, an additional statistical distribution, POLO (power log normal; McGill 2003b), could be also regarded as a model for revealing community structure. POLO covers both log normal and power law: log normal becomes power law at the limit of infinite standard deviation after taking the logarithm (Pueyo 2006b). The ubiquitous property of POLO could be further checked to evaluate structural property residing in benthic macroinvertebrate communities in complex situations of polluted stream ecosystems.

This study also demonstrated that SADs were efficient in presenting community structure in a stable manner where environmental factors could not be readily differentiated in a limited range in stressful conditions. SADs in the Suyong Stream were substantially differentiable (Fig. 2b), while environmental measurements were not distinctively different (Table 1). The stable SAD curves were also observed at the sample sites in the Yangjae Stream (Fig 3). Although environmental factors did not strongly reflect the improvement of the water quality (Table 1), differences in SADs were observable between different sampling times (i.e., the first year and the following years) and between different locations (i.e., upstream vs. downstream) in the Yangjae Stream (Figs. 1, 3). Improvement of habitats could be confirmed with change in biological factors as shown in increase in species richness (Fig. 4). The structural property in the species-abundance relationships could be efficiently illustrated through SADs in response to natural and anthropogenic disturbances in stream ecosystems.

\section{Conclusions}

SADs in benthic macroinvertebrates were suitable for representing the states of communities in response to disturbances in streams. In field conditions, the log normal distribution appeared fitted to sampled data mostly among the conventional models in SAD, while the geometric series was selectively acceptable for the communities under severely polluted conditions. The power law was suitable for generally analyzing SADs and the parameter $(\beta)$ reflected the state of community conditions in benthic macroinvertebrates. Overall, SADs were efficient in representing community states where the environmental factors could not clearly differentiate community state in disturbed streams.

\section{Acknowledgment}

This research was supported by Korea Ministry of Environment as "National Long-Term Ecological Project." Xiaodong Qu is supported by Brain Korea 21 Program of the Korean Ministry of Education (Brain Korea 21 program).

\section{References}

Allan J.D. \& Castillo M.M. 2007. - Stream ecology: structure and function of running waters. $2^{\text {nd }}$ edition. Springer, Dordrecht, Netherlands, $436 \mathrm{p}$.

Arrhenius O. 1921. - Species and area. J. Ecol., 9, 95-99.

Bae Y.-S. \& Park S.-B. 1992. - Benthic invertebrate community and relation with environmental factors at the ecosystem of tributary stream in Han River. Kor. J. Lim., 25, 41-57.

Barbour M.T., Gerritsen J., Snyder B.D. \& Stribling J.B. 1999. Rapid bioassessment protocols for use in streams and wadeable rivers: periphyton, benthic macroinvertebrates and fish. $2^{\text {nd }}$ edition. EPA 841-B-99-002., U.S. Environmental Protection Agency, Office of Water, Washington, D.C.

Begon M., Townsend C.R. \& Harper J.L. 2006. - Ecology: from individuals to ecosystems. $4^{\text {th }}$ edition. Blackwell, Malden, MA. $738 \mathrm{p}$.

Chave J., Muller-Landau H.C. \& Levin S.A. 2002. - Comparing classical community models: theoretical consequences for patterns of diversity. Am. Nat., 159, 1-23.

Chave J. 2004. - Neutral theory and community ecology. Ecol. Lett., 7. 241-253.

Chon T.-S. \& Kwon T.-S. 1991. - Ecological studies on benthic macroinvertebrates in the Suyong River I. Investigations on community structures and biological indices in the lower reach. Kor. J. Lim., 24, 165-178.

Chon T.-S., Park Y.-S. \& Park J.-H. 2000. - Determining temporal pattern of community dynamics by using unsupervised learning algorithms. Ecol. Model., 132, 151-166.

Chon T.-S., Kwak I.-S., Song M.-Y., Park Y.-S., Cho H.-D, Kim M.-J., Cha E.-Y. \& Lek S. 2002. - Benthic macroinvertebrates in streams of South Korea in different levels of pollution and patterning of communities by implementing the self-organizing mapping. Pages 356-384 in Ecology of Korea. Lee D. (eds). Bumwoo Publishing Company, Seoul.

del Moral R. 1999. - Plant succession on pumice at Mount St. Helens, Washington. Am. Mid. Nat., 141, 101-114.

Fisher R.A., Corbet A.S. \& Williams C.B. 1943. - The relation between the number of species and the number of individuals in a random sample of an animal population. J. Anim. Ecol., 12, $42-58$.

Gleason H.A. 1922. - On the relation between species and area. Ecology, 3, 158-162.

Gray J.S. \& Mirza F.B. 1979. - A possible method for the detection of pollution-induced disturbance on marine benthic communities. Mar. Poll. Bull., 10, 142-146

Gray J.S. 1981. - Detecting pollution induced changes in communities using the log-normal distribution of individuals among species. Mar. Poll. Bull., 25, 48-50

Harte J., Kinzig A. \& Green J. - Self-similarity in the distribution and abundance of species. Science, 284, 334-336.

Hellawell J.M. 1986. - Biological indicators of freshwater pollution and environmental management. Elsevier, Amsterdam, 446 p.

Hubbell S.P. 1997. - A unified theory of biogeography and relative species abundance and its application to tropical rain forests and coral reefs. Coral Reefs, 16, Suppl., 9-21.

Hubbell S.P. 2001. - The unified neutral theory of biodiversity and biogeography. Princeton University Press, Princeton, 369p.

Hughes R.G. 1984. - A model of the structure and dynamics of benthic marine invertebrate communities. Mar. Ecol. Prog. Ser., $15,1-11$.

Jackson C.R. Perry F.C. \& Roden E.E. 2001. - Successional changes in bacterial assemblage structure during epilithic biofilm development. Ecology, 82, 555-566. 
James A. \& Evison L. 1979. - Biological indicators of water quality. John Wiley and Sons, New York, 597p.

KICT (Korea Institute of Construction Technology). 1997. Development of close-to nature river improvement techniques (CTNRIT) adapted to the Korean streams. Report, Vol. 2, KICT, Seoul.

KICT. 1999. - Development of conservation, rehabilitation, and creation techniques of natural environment for the coexistence of man with nature. Development of close-to-nature river improvement techniques adapted to the Korean streams. Vol. I, KICT, Seoul.

Kwak I.-S., Song M.-Y. \& Chon T.-S. 2002. - Community of benthic macroinvertebrates at different habitats in a polluted urbanised stream. Kor. J. Lim., 35, 295-305.

Kwon T.-S. \& Chon T.-S. 1991. - Ecological studies on benthic macroinvertebrates in the Suyong River II. Investigations on distribution and abundance in its main stream and four tributaries. Kor. J. Lim. 24, 179-198.

Kwon T.-S. \& Chon T.-S. 1993. - Ecological studies on benthic macroinvertebrates in the Suyong River. III. Water quality estimations using chemical and biological indices. Kor. J. Lim., 26, 105-128.

MacArthur R.H. 1957. - On the relative abundance of bird species. Proc. Nat. Acad. Sci., 43, 293-295.

MacArthur R.H. 1960. - On the relative abundance of species. Am. Nat., 94, 25-36.

MacArthur R.H. \& Wilson E.O. 1967. -The theory of island biogeography. Princeton University Press, Princeton, NJ, 224p.

Magurran A. E. 1988. - Ecological diversity and its measurement. Chapman \& Hall, London, UK, 179p.

Magurran A.E. \& Henderson P.A. 2003. -Explaining the excess of rare species in natural species abundance distributions. Nature, 422, 714-716.

Magurran A.E. 2004. - Measuring biological diversity. Blackwell, Oxford, UK, 256p.

May R.M. 1975. -Patterns of species abundance and diversity. Pages 81-120 in Ecology of species and communities. Cody M. \& Diamond J.M. (eds). Harvard University Press, Cambridge, MA.

May R.M., Crawley M.J. \& Sugihara G. 2007. - Communities: patterns. Pages 111-131 in Theoretical ecology: principles and applications. May R.M. \& McLean A.R. (eds). Oxford University Press, Oxford, UK.

McGill B. 2003a. - A test of the unified neutral theory of biodiversity. Nature, 422, 881-885.

McGill B. 2003b. - Strong and weak tests of macroecological theory. Oikos, 102, 679-685.

McKane A.J., Alongso D. \& Solé R.V. 2004. - Analytic solution of Hubbell's model of local community dynamics. Theor. Pop. Biol., 65, 67-73.

Motomura I. 1932. - On the statistical treatment of communities. Zool. Mag. Tokyo, 44, 379-383.

Oh Y.-N. \& Chon T.-S. 1991a. -A study on the benthic macroinvertebrates in the middle reaches of the Paenae stream, a tributary of the Nakdong River, Korea. I. Community analysis and biological assessment of the water quality. Kor. J. Ecol., 14, 345-360.

Oh, Y.-N. \& Chon T.-S. 1991b. -A study on the benthic macroinvertebrates in the middle reaches of Paenae stream, a tributary of the Naktong River, Korea II. Comparison of communities and environments at the upper and lower sites of levees. Kor. J. Ecol., 14, 399-413.

Oh, Y.-N. \& T.-S. Chon. 1993. -A study on the Benthic macroinvertebrates in the middle reaches of Paenae stream, a tributary of the Naktong River, Korea III. Drifting aquatic insects in four seasons. Kor. J. Ecol., 16, 489-499.

Patrick R. 1975. -Structure of stream communities. Pages 445-459 in Ecology of species and communities. Cody M. \& Diamond J.M. (eds). Harvard University Press, Cambridge, MA.

Park J.-H. \& Cho K.-S. 1995. -Ecological characteristics of the aquatic insects community of Pangtae Creek in Kangwon-do. Kor. J. Ecol., 28, 309-322.

Park Y.-S., Chon T.-S., Kwak I.-S. \& Lek S. 2004. -Hierarchical community classification and assessment of aquatic ecosystems using artificial neural networks. Sci. Total. Environ. 327, 105-122.

Park Y.-S., Song M.-Y., Park Y.-C., Oh K.-H., Cho E.-C. \& Chon T.-S. 2007. -Community patterns of benthic macroinvertebrates collected on the national scale in Korea. Ecol. Model., 203, 26-33.

Preston F.W. 1948. -The commonness and rarity of species. Ecology, 29, 254-283.

Pueyo S. 2006a. -Self-similarity in species-area relationship and in species abundance distribution. Oikos, 112, 156-162.

Pueyo S. 2006b. -Diversity: between neutrality and structure. Oikos, 112, 392-405.

Resh V.H. \& Rosenberg D.M. 1984. -The ecology of aquatic insects. Praeger, New York, 625p.

Resh V.H., Norris R.H. \& Barbour M.T. 1995. -Design and implementation of rapid assessment approaches for water resource monitoring using benthic macroinvertebrates. Aust. J. Ecol. 20, 108-121.

Rosenberg D.M. \& Resh V.H. 1993. -Freshwater biomonitoring in benthic macroinvertebrates. Chapman and Hall, New York. 488p.

Sokal R R. \& Rohlf F.J. 1995. - Biometry: the principles and practice of statistics in biological research. $3^{\text {rd }}$ edition. W.H. Freeman and Company, New York, 887p.

Song M.-Y., Park Y.-S., Kwak I.-S., Woo H.-S. \& Chon T.-S. 2006. Characterization of benthic macroinvertebrate communities in a restored stream by using self-organizing map. Ecol. Infor., 1, 295-305.

Statzner B., Gore J.A. \& Resh V.H. 1988. - Hydraulic stream ecology: observed patterns and potential applications. J. N. Am. Benthol. Soc., 7, 307-360.

Sugihara G. 1980. -Minimal community structure: an explanation of species abundance patterns. Am. Nat., 116, 770-787.

Tokeshi M. 1993. Species abundance patterns and community structure. Adv. Ecol.Res., 24, 112-186.

Tokita K. 2004. -Species abundance patterns in complex evolutionary dynamics. Phys. Rev. Lett., 93, 178102-1-4.

Tokita K. 2006. - Statistical mechanics of relative species abundance. Ecol. Infor., 1, 315-324.

Volkov I, Banavar J.R., Hubbell S.P. \& Maritan A. 2003. - Neutral theory and relative abundance in ecology. Nature, 424, 10351037.

Whittaker R.H. 1965. -Dominance and diversity in land plant communities. Science, 147, 250-260.

Whittaker R.H. 1975. -Communities and ecosystems. $2^{\text {nd }}$ Rev edition. Macmillan, New York, 352p.

Wright J.F., Sutcliffe D.W. \& Furse M.T. 2000. -Assessing the biological quality of fresh waters: RIVPACS and other techniques. Freshwater Biological Association, Ambleside, UK, 400p.

Youn B.-J. \& Chon T.-S. 1996. Community analysis in chironomids and biological assessment of water qualities in the Suyong and Soktae streams of the Suyong River. Kor. J. Lim., 29, 275-289. 
Appendix I. Parameters characterizing the geometric and log series in species abundance distribution of benthic macroinvertebrate communities collected in the Suyong River, Yangjae Stream, and reference sites in Korea. (Parameters are defined in the text.)

\begin{tabular}{cccccc}
\hline & & Geometric series & & \multicolumn{2}{c}{ Log series } \\
\cline { 3 - 3 } \cline { 5 - 6 } Streams & Sites & $\mathrm{k}$ & & $\alpha$ & $\chi$ \\
\cline { 5 - 6 } Soktae & $\mathrm{T} 1$ & 0.069 & & 11.272 & 0.99969 \\
& $\mathrm{~T} 2$ & 0.095 & & 8.104 & 0.99971 \\
& $\mathrm{~T} 3$ & 0.289 & & 2.477 & 0.99986 \\
& $\mathrm{~T} 4$ & 0.347 & & 2.019 & 0.99992 \\
\hline Suyong & $\mathrm{Y} 1$ & 0.086 & & 9.086 & 0.99981 \\
& $\mathrm{Y} 2$ & 0.081 & & 9.911 & 0.99990 \\
& $\mathrm{Y} 3$ & 0.087 & & 8.951 & 0.99979 \\
\hline Yangjae & $\mathrm{J}_{\mathrm{f}}$ & 0.561 & & 1.186 & 0.99999 \\
& $\mathrm{~J}_{\mathrm{S}}$ & 0.378 & & 2.160 & 0.99999 \\
& $\mathrm{~J}_{\mathrm{t}}$ & 0.390 & & 2.078 & 0.99997 \\
& $\mathrm{All}$ & 0.314 & & 2.696 & 0.99999 \\
\hline Hakjang & $\mathrm{K}$ & 0.260 & & 3.398 & 0.99965 \\
\hline Paenae & $\mathrm{B}$ & 0.055 & 15.825 & 0.99960 \\
\hline Pangtae & $\mathrm{P}$ & 0.038 & 25.754 & 0.99655 \\
\hline Chojong & $\mathrm{C}$ & 0.050 & 19.732 & 0.99953 \\
\hline
\end{tabular}

Appendix II. Parameters characterizing the geometric series, log series and log normal model in species abundance distribution of benthic macroinvertebrate communities collected in the Yangjae stream. (Parameters are defined in the text.)

\begin{tabular}{|c|c|c|c|c|c|c|c|c|c|c|c|c|c|c|c|}
\hline \multirow{3}{*}{ Sites } & \multirow{2}{*}{\multicolumn{3}{|c|}{$\begin{array}{c}\begin{array}{c}\text { Geometric } \\
\text { series }\end{array} \\
k\end{array}$}} & \multicolumn{6}{|c|}{ Log series } & \multicolumn{6}{|c|}{ Log normal distribution } \\
\hline & & & & \multicolumn{3}{|c|}{$\alpha$} & \multicolumn{3}{|c|}{$\chi$} & \multicolumn{3}{|c|}{$a$} & \multicolumn{3}{|c|}{$\gamma$} \\
\hline & $\mathrm{J}_{\mathrm{f}}$ & $\mathrm{J}_{\mathrm{S}}$ & $\mathrm{J}_{\mathrm{t}}$ & $\mathrm{J}_{\mathrm{f}}$ & $\mathrm{J}_{\mathrm{S}}$ & $\mathrm{J}_{\mathrm{t}}$ & $\mathrm{J}_{\mathrm{f}}$ & $\mathrm{J}_{\mathrm{s}}$ & $\mathrm{J}_{\mathrm{t}}$ & $\mathrm{J}_{\mathrm{f}}$ & $\mathrm{J}_{\mathrm{S}}$ & $\mathrm{J}_{\mathrm{t}}$ & $\mathrm{J}_{\mathrm{f}}$ & $\mathrm{J}_{\mathrm{S}}$ & $\mathrm{J}_{\mathrm{t}}$ \\
\hline $\mathrm{J} 1$ & 0.78 & 0.45 & 0.39 & 0.72 & 1.72 & 2.09 & 0.99994 & 0.99984 & 0.99953 & 0.18 & 0.17 & 0.23 & 2.36 & 1.69 & 1.44 \\
\hline $\mathrm{J} 2$ & 0.67 & 0.38 & 0.42 & 0.97 & 2.17 & 1.88 & 0.99991 & 0.99984 & 0.99980 & 0.15 & 0.18 & 0.20 & 2.15 & 1.53 & 1.47 \\
\hline $\mathrm{J} 3$ & 0.72 & 0.56 & 0.46 & 0.79 & 1.29 & 1.71 & 0.99986 & 0.99981 & 0.99973 & 0.17 & 0.19 & 0.21 & 2.40 & 2.19 & 1.39 \\
\hline $\mathrm{J} 4$ & 0.64 & 0.49 & 0.42 & 0.91 & 1.41 & 1.92 & 0.99995 & 0.99990 & 0.99932 & 0.18 & 0.19 & 0.24 & 2.33 & 1.74 & 1.77 \\
\hline J5 & 0.69 & 0.54 & 0.50 & 0.91 & 1.35 & 1.49 & 0.99995 & 0.99994 & 0.99984 & 0.17 & 0.18 & 0.20 & 2.51 & 2.35 & 2.07 \\
\hline J6 & 0.78 & 0.51 & 0.56 & 0.67 & 1.35 & 1.28 & 0.99997 & 0.99993 & 0.99991 & 0.14 & 0.17 & 0.18 & 2.92 & 1.92 & 1.65 \\
\hline J7 & 0.74 & 0.47 & 0.47 & 0.79 & 1.62 & 1.63 & 0.99996 & 0.99991 & 0.99982 & 0.16 & 0.17 & 0.19 & 2.65 & 1.45 & 1.45 \\
\hline J8 & 0.86 & 0.69 & 0.45 & 0.47 & 0.91 & 1.60 & 0.99998 & 0.99995 & 0.99984 & 0.15 & 0.15 & 0.21 & 2.70 & 2.79 & 1.40 \\
\hline J9 & 0.68 & 0.46 & 0.46 & 0.93 & 1.67 & 1.67 & 0.99994 & 0.99988 & 0.99977 & 0.15 & 0.18 & 0.21 & 2.23 & 1.85 & 1.58 \\
\hline $\mathrm{J} 10$ & 0.79 & 0.50 & 0.50 & 0.52 & 1.50 & 1.51 & 0.99993 & 0.99966 & 0.99964 & 0.19 & 0.19 & 0.23 & 2.20 & 1.74 & 1.81 \\
\hline J11 & 0.87 & 0.54 & 0.51 & 0.52 & 1.35 & 1.50 & 0.99993 & 0.99972 & 0.99967 & - & 0.18 & 0.18 & - & 1.50 & 1.48 \\
\hline
\end{tabular}


